\title{
Evidence of Hot Fluid Flows in the Sandstone-type Uranium Deposit in the Kailu Basin, Northeast China
}

FEI XiA ${ }^{1 *}$, FENGJUN NiE ${ }^{1}$, JiNHUI LIU ${ }^{1}$,ZHAOBING YAN ${ }^{1}$, BAI GAO ${ }^{1}$, XUEGANG WANG ${ }^{1}$, ZHIBING FENG ${ }^{1}$

${ }^{1}$ State key laboratory of nuclear resources and environment , East China University of Technology, China (*e-mail: fxia@ecit.cn,fjnie@ecit.cn,liujh1961@163.com, zhbyan@ecit.cn,gaobai@ecit.cn, xgwang@ecit.cn,zhbfeng@ecit.cn)

Introduction:The discovery of the QianjiadianBaolongshan uranium deposit (QBUD) in the Kailu basin extremely encourages explorers to look for in-situ leaching uranium deposits (ISLUD) in the post-Jurassic extensional basins in Northeast China. The thermal fluid flows characteristics of the deposit are obvious, it is estimated that $70 \% \sim 80 \%$ of the exploration drilling holes meet the diabase beds. The core observation, microscope, electronic microprobe and inclusion temperature and salinity provide four kinds of evidence.

Results:Detailed petrographic analysis was conducted to diabase from the Qianjiadian-Baolongshan uranium deposit. The fine sandstone and mudstone conglomerate blackened by heat (Fig.1-A), the shaly thin layers of mudstone and sandstone are baked to a dark purple(Fig.1-B), and the large number of carbonate veins interspersed in mudstone(Fig.1D), besides, the main temperature range of fluid inclusion temperature is $110-120^{\circ} \mathrm{C}$.

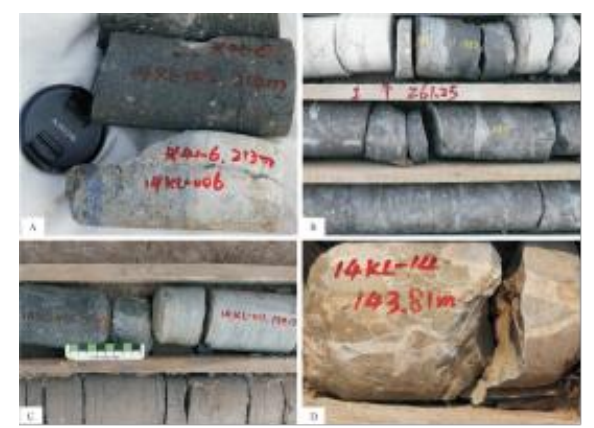

Fig.1 Rock alterations caused by the diabase intrusion

This research was jointly supported by the National natural Science Foundation of China (Grant No. 41862010).

[1] NIE Fengjun, YAN Zhaobin, XIA Fei, LI Mangen, LU Yayun, CAI Jianfang,GUO Funeng, NING Jun (2017) GEOLOGICAL BULLETIN OF CHINA, 36(10), 1850-1866. 